\title{
DIODE-GRIDS FOR MILLIMETER-WAVE PHASE-SHIFTERS AND FREQUENCY DOUBLERS
}

\author{
Wayne W. Lam, Howard Chen, David B. Rutledge \\ Division of Engineering and Applied Science \\ California Institute of Technology \\ Pasadena, CA 91125 \\ Christina F. Jou, and Neville C. Luhmann, Jr. \\ Department of Electrical Sciences \\ University of California, Los Angeles \\ Los Angeles, CA 90024
}

\begin{abstract}
Diode-grids have been fabricated on 2-cm square monolithic gallium-arsenide wafers with 1600 Schottky varactor-diodes. A computer-controlled reflectometer that uses a wave-front division interference technique was developed to measure the reflection coefficient of the diode-grids. A $70^{\circ}$ phase shift with a 6-dB loss was obtained at $93 \mathrm{GHz}$ when the bias on the diode-grid was changed from $-3 \mathrm{~V}$ to $+1 \mathrm{~V}$. A second harmonic conversion efficiency of $16 \%$ and an output power of $0.5 \mathrm{~W}$ was obtained at $66 \mathrm{GHz}$ when the diode-grid was pumped with a pulsed magnetron at $33 \mathrm{GHz}$.
\end{abstract}

\section{Introduction}

Designs based diode-grids were proposed for electronic beam-steering and frequency multiplication [1]. Fig. 1 shows these designs and the left of Fig. 2 shows part of a fabricated diode-grid. In the beam-steering array, the incident beam reflects off a pair of diode-grids, where the diode bias controls the phase of the reflected wave. The idea is to program a progressive phase shift across the aperture to steer the reflected beam. In the frequency-doubling array, power at the fundamental frequency enters through the input filter, arrives at the varactor-diode grid, and pumps the diodes to generate the harmonics. The second harmonic is filtered out through the output filter.
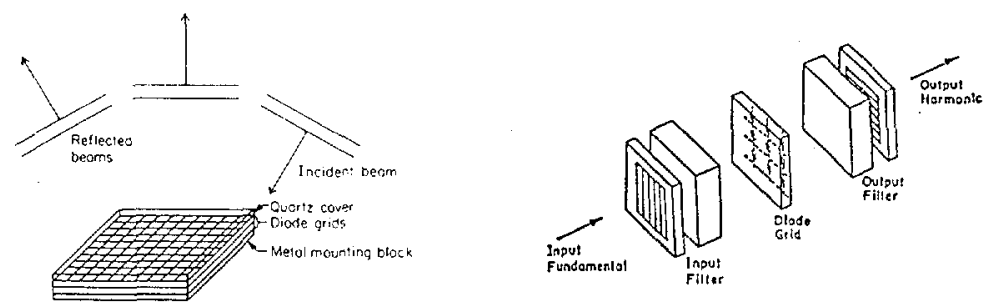

Figure 1. (Left.) Electronic beam-steering array. (Right.) Frequency-doubling array. CH2435-6/87/0000-1190\$01.00 @ 1987 IEEE 


\section{Technique of Measurement}

The right of Fig. 2 shows a computer-controlled reflectometer developed to measure the reflection coefficient of the diode-grid. The idea is to use an absorbing screen with a hole in the center to divide an incident wave-front two parts. The wave that reflects off the absorber is the reference, while the other part reflecting off the diode-grid is the signal. The interference of these waves is measured as the sample is translated relative to the absorber. The phase and amplitude of the reflection coefficient of the diode-grid may be found by leastsquare fitting each interference pattern or by a simple four-point method [2].
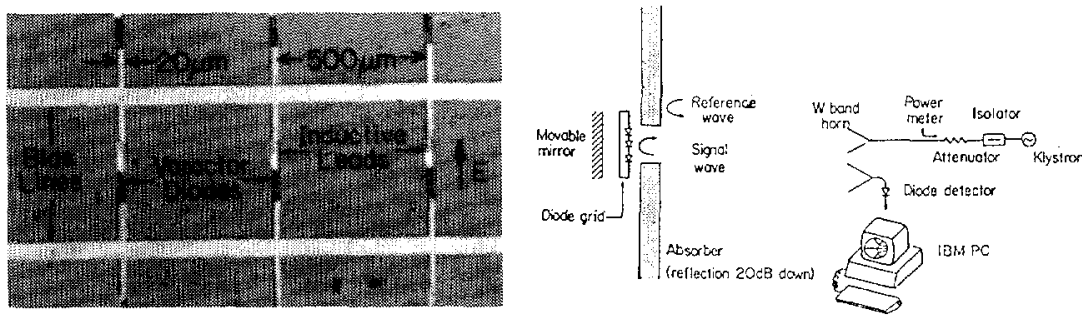

Figure 2. (Left) Part of a diode-grid fabricated on a gallium-arsenide wafer. (Right) Quasi-optical reflectometer for millimeter-waves.

\section{Discussion and Results}

A family of tuning curves of a diode-grid was measured with different DC biases on the grid as the mirror was scanned behind it. Fig. 3 shows the zerobias tuning curve measured at $94 \mathrm{GHz}$. The measured phase and reflectance were curve-fitted with a model based on transmission-line theory. Four fitting parameters were used. The first parameter, phase calibration length, is the thickness of an air layer inserted in front of the diode-grid to account for inaccuracy in phase calibration. It allows the calculated phase curve to adjusted by a constant offset. The second parameter, initial mirror separation, is the thickness of an air layer inserted between the diode-grid and the mirror to account for inaccuracy in measuring their initial separation. This has the effect of adjusting the calculated phase and reflectance horizontally. The last two parameters are the real and imaginary parts of the diode-grid impedance. On this basis, theoretical curves were plotted using the best-fitted phase calibration length $(792 \mu \mathrm{m})$, initial mirror separation $(1663 \mu \mathrm{m})$ and diode-grid impedance $(58+j 94 \Omega)$, the measured average wafer thickness $(376 \mu \mathrm{m})$, and the published refractive index for GaAs (3.6 from Afsar el at. [3]). From the measured grid period $(504 \mu \mathrm{m})$, strip width $(18 \mu \mathrm{m})$, and strip length $(450 \mu \mathrm{m})$, the calculated reactance due to the strip at $94 \mathrm{GHz}$ is $153 \Omega$. Subtracting this value from the total diode-grid reactance as measured in the curve-fitting procedure, the capacitive reactance due to the diode is $59 \Omega$. This corresponds to a zero bias capacitance of $29 \mathrm{fF}$. The zero bias capacitance measured at $1 \mathrm{MHz}$ has 
an average of $30 \mathrm{fF}$ and a standard deviation of $10 \mathrm{fF}$, and the series resistance measured at DC has an average of $78 \Omega$ and a standard deviation of $19 \Omega$.
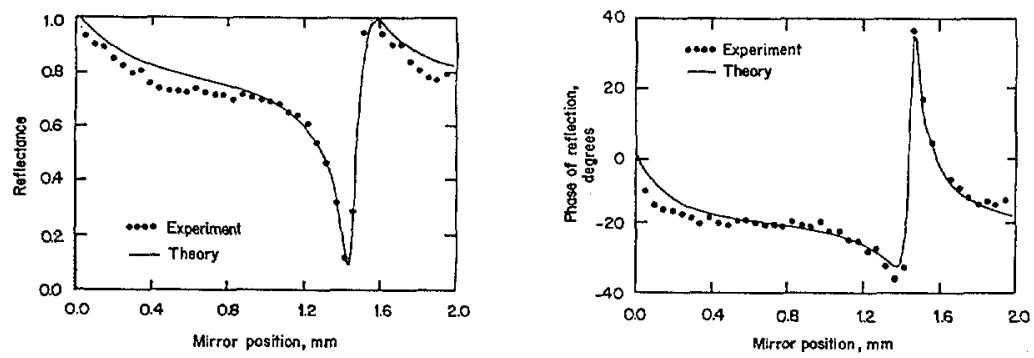

Figure 3. Measured reflectance and phase of reflection of diode-grid at $94 \mathrm{GHz}$.

Following the curve-fitting procedure described above, the capacitancevoltage (C-V) characteristic of the same diode-grid was measured at $94 \mathrm{GHz}$. Fig. 4 shows the result and compares it to the $\mathrm{C}-\mathrm{V}$ curve measured with the $\mathrm{Hp} 4280 \mathrm{~A} \mathrm{C}-\mathrm{V}$ meter at $1 \mathrm{MHz}$. The comparisons is also complicated by the fact that the wafer thickness varies from $370 \mu \mathrm{m}$ to $385 \mu \mathrm{m}, 4$ out of 40 rows of the diode-grid were shorted and could not biased, and the parasitic capacitance of the diodes cannot be measured accurately at the low frequency.

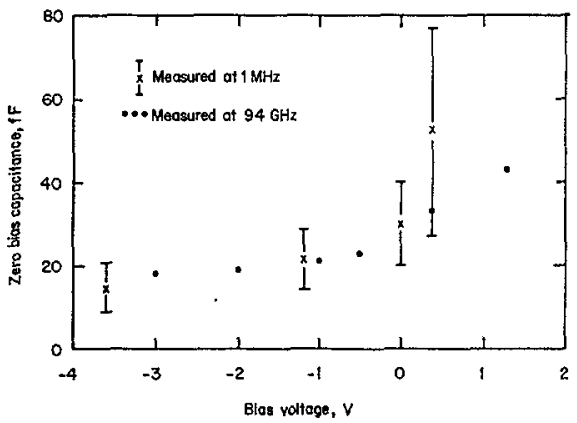

Figure 4. Measured capacitance-voltage characteristic at $94 \mathrm{GHz}$ and at $1 \mathrm{MHz}$. Bars indicate on standard deviation.

Phase shift performance was measured at $93 \mathrm{GHz}$ with another diode-grid that has a lower series resistance. Fig. 5 shows the configuration in which this measurement was made and a comparison between theory and experiment. A $70^{\circ}$ phase shift with a 6-dB loss was obtained. The diode-grid impedance was measured in this configuration following the curve-fitting procedure outlined above. The measured values were $(26+j 62 \Omega)$. The largest phase shift occurred when the mirror was placed $1.49 \mathrm{~mm}$ from the diode-grid. Theoretical curves were plotted using the measured series resistance $(26 \Omega)$, fused quartz 
thickness $(434 \mu \mathrm{m})$, average wafer thickness $(218 \mu \mathrm{m})$, and the calculated inductive reactance $(151 \Omega)$. In addition, we assumed the initial mirror separation was $1.45 \mathrm{~mm}$, the refractive index for fused quartz and GaAs were 1.96 and $\widetilde{3} .6$ respectively [3], the phase calibration length was $1 \mathrm{~mm}$, and the diode capacitance varied from $35 \mathrm{fF}$ at $+0.9 \mathrm{~V}$ to $18 \mathrm{fF}$ at $-2.75 \mathrm{~V}$. The measured initial mirror separation was $1.49 \mathrm{~mm}$, the phase calibration length was $0.91 \mathrm{~mm}$, and the average diode capacitance was $27 \mathrm{fF}$ at zero bias and $20 \mathrm{fF}$ at $-3 \mathrm{~V}$. The wafer thickness varied from $210 \mu \mathrm{m}$ to $230 \mu \mathrm{m}$ and 3 out of 35 rows of the diode-grid were shorted and cannot be biased. Sensitivity analysis indicates that phase is strongly dependent on wafer thickness and initial mirror separation, shifting vertically by one degree per micron for each.
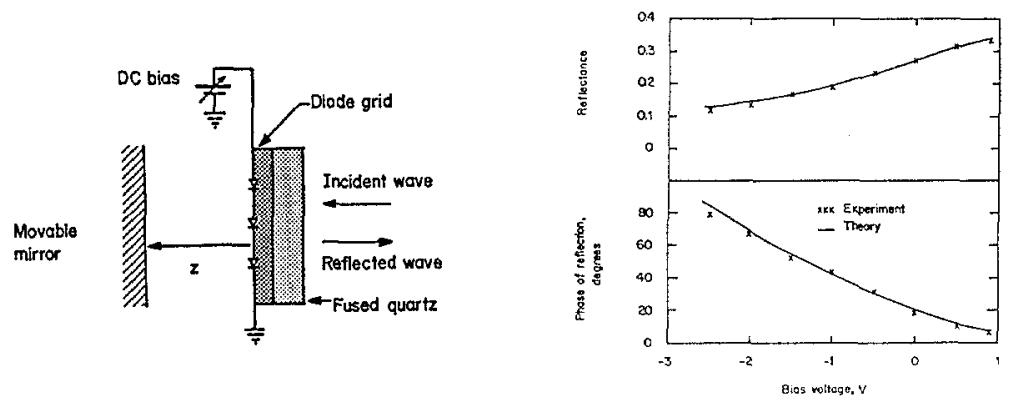

Figure 5. (Left) Diode-grid configuration for reffection measurement at $93 \mathrm{GHz}$. (Right) Measured phase shift performance of a diode-grid at $93 \mathrm{GHz}$.

Doubling efficiency of the diode-grid that was used in the phase shift experiment was measured for frequency doubling from $33 \mathrm{GHz}$ to $66 \mathrm{GHz}$. A pulsed magnetron is used to pump the diode-grid. The highest efficiency achieved was $16 \%$, with an output power of $0.5 \mathrm{~W}$.

\section{Acknowledgements}

This work was supported by the Army Research Office, the U.S. Army Harry Diamond Laboratory, the Jet Propulsion Laboratory, and by TRW under the University of California MICRO program. Wayne Lam acknowledges the support of an AMOCO Foundation Fellowship.

\section{References}

[1] W. W. Lam, C. F. Jou, N. C. Luhmann, Jr., and D. B. Rutledge, "Diode Grids for Electronic Beam Steering and Frequency Multiplication," Int. J. of Infrared and Millimeter Waves, 7, pp. 27-41, 1986.

[2] J. C. Wyant, "Interferometry for Three-dimensional Sensing," Test and Measurement World, April, pp. 66-71, 1986.

[3] M. N. Afsar and K. J. Button, "Millimeter-Wave Dielectric Properties of Materials," Infrared and Millimeter Waves, Chap. 1, pp, 1-41, K. J. Button, ed., Academic Press, Inc., New York, 1981. 